\title{
The Clinical Utility and Safety of Radiofrequency Ablation for Malignant Lung Tumors: Preliminary Results
}

\author{
1) Department of Diagnostic and Interventional Radiology, Aichi Cancer Center Hospital, Aichi, Japan \\ 2) Department of Thoracic Surgery, Aichi Cancer Center Hospital, Aichi, Japan \\ 3) Department of Radiation Oncology, Aichi Cancer Center Hospital, Aichi, Japan
}

Takaaki Hasegawa $^{1)}$, Yozo Sato ${ }^{1)}$, Yoshitaka Inaba ${ }^{1)}$, Hiroaki Kuroda ${ }^{2)}$, Natsuo Tomita ${ }^{3)}$, Yukinori Sakao ${ }^{2)}$

\section{Abstract}

Purpose: We evaluated the clinical usefulness and safety of radiofrequency ablation (RFA) for the treatment of lung tumors.

Materials and Methods: This retrospective study included patients who underwent RFA for the treatment of lung tumors at our institution from March 2006 to April 2015. Technical success, safety, local tumor progression, and survival were evaluated.

Results: In total, 41 patients (28 men and 13 women; median age, 69 years; range 37-88 years) with 51 malignant lung tumors measuring 0.6-6.8 cm (mean, $1.7 \pm 1.2 \mathrm{~cm}$ ) completed 46 planned RFA sessions. Lung tumors were primary in 22 patients and metastatic in 19 patients. Four tumors were not completely surrounded by an ablation zone on computed tomography immediately after RFA (technical success rate; $91.3 \%$, 42/46). One of 41 patients (2.4\%) died of pneumonia in the contralateral lung 26 days after RFA. Grade 2 symptomatic pneumothorax $(\mathrm{n}=5)$ and hemothorax $(\mathrm{n}=1)$ and grade 1 asymptomatic pneumothorax $(\mathrm{n}=9)$ occurred during the procedure. Grade 3 pneumonia $(\mathrm{n}=1)$ and grade 2 fever $(\mathrm{n}=2)$ occurred within 30 days of follow-up. During a mean follow-up period of $20.3 \pm 19.1$ months, local tumor progression developed in 8 of 51 tumors $(15.7 \%)$. Eleven patients $(26.8 \%)$ died of cancer progression $(n=9)$ or pneumonia $(n=2)$. The 5-year overall survival rate was 53.5\% (95\% confidence interval, 31.1-75.9\%). Tumor size was a significant prognostic factor on Cox proportional hazards analysis.

Conclusion: RFA was a safe and useful treatment option for malignant lung tumors.

Key words: Interventional radiology, Lung neoplasms, Radiofrequency ablation

(Interventional Radiology 2017; 2: 25-32)

\section{INTRODUCTION}

Lung cancer is the most life-threatening type of tumor; specifically, primary lung cancer is the most common malignancy and the leading cause of cancer-related mortality [1]. The lung is also one of the most frequent sites of metastasis from many types of malignant neoplasms, leading to apnea or dyspnea and morbidity [2-5].

Pulmonary lobectomy is the recommended standard of treatment for early stage non-small cell lung cancer (NSCLC) [6, 7]. Surgical resection has been reported to result in better survival than systemic chemotherapy in selected patients with metastatic lung cancer [8-10]. However, some patients cannot undergo surgery because of poor respiratory function, advanced age, or comorbid disease.

Recently, radiofrequency ablation (RFA) of the lung for patients who are not surgical candidates has been reported to achieve comparable results to surgical resection [11-19]. However, the availability of this treatment in Japan and re- 
ports on its outcomes from this country are limited because of lack of coverage within the national health insurance system. In the present study, we evaluated the clinical utility and safety of lung RFA for patients at our institution with unresectable malignant lung tumors.

\section{MATERIALS AND METHODS}

\section{Study design and patients}

This retrospective study included patients who underwent RFA for malignant lung tumors at our institution from March 2006 to April 2015. Our institutional review board approved this study. The necessity for informed consent for study inclusion was waived, but informed consent to undergo lung RFA was obtained from all patients before every procedure.

Patient and tumor characteristics are presented in Table $\mathbf{1 .}$ The study included 41 patients (median age, 69 years; range, 37-88 years), comprising 28 men and 13 women.

The indication for lung RFA was determined based on discussion among thoracic surgeons, radiation oncologists, and interventional radiologists in our hospital. Lung RFA was performed in patients who were not considered candidates for surgery or stereotactic body radiation therapy, or in those who declined to undergo these treatments. Thirty-nine of the 41 patients $(95.1 \%)$ were not considered surgical candidates because of insufficient respiratory function $(n=29)$, existence of extrapulmonary lesions $(n=5)$, age over 75 years $(n=4)$, or uncontrolled diabetes $(n=1)$. Two of the 41 patients $(4.9 \%)$ received RFA per request.

The criteria for lung RFA treatment were the following: 1) lung tumor considered treatable using RFA; 2) no or controlled extrapulmonary tumor; 3) peripheral capillary oxygen saturation level of $92 \%$ or higher when breathing room air; 4) Eastern Cooperative Oncology Group performance status of 0 or 1 [20]; and 5) life expectancy of 2 months or longer. A tumor was considered to be treatable using lung RFA if there was a safe puncture route, even if the route contacted large vessels or pleura. In contrast, a tumor was considered untreatable using lung RFA when it was too large to allow complete ablation or when puncture was technically difficult because of the presence of bone, vessels, bronchi, or the heart in the puncture route. At the beginning of this study, we performed lung RFA with curative intent for tumors up to $10 \mathrm{~cm}$; however, we then realized that complete ablation was difficult to achieve for tumors larger than $3 \mathrm{~cm}$. We therefore performed RFA with curative intent only for tumors less than $3 \mathrm{~cm}$ in size for the rest of this study. $\mathrm{Pa}-$ tients with abnormal coagulation test results, such as platelet count $<50,000 / \mathrm{mL}$ or prothrombin international normalized ratio (INR) of $>1.5$, were excluded.

Twenty-two patients had primary non-small cell lung cancer (NSCLC) and 19 had pulmonary metastasis from, respectively, colorectal cancer $(n=12)$, hepatocellular carcinoma $(n=3)$, renal cell carcinoma $(n=2)$, gastric cancer $(n$
Table 1. Patient and tumor backgrounds

\begin{tabular}{|c|c|}
\hline \multicolumn{2}{|l|}{ Variables } \\
\hline \multicolumn{2}{|l|}{ Patient characteristics } \\
\hline Number & 41 \\
\hline \multicolumn{2}{|l|}{ Sex } \\
\hline Female & 13 \\
\hline Male & 28 \\
\hline Median Age(years) & 69 \\
\hline \multicolumn{2}{|l|}{ Extra-pulmonary lesion } \\
\hline Yes & 7 \\
\hline No & 34 \\
\hline \multicolumn{2}{|l|}{ Tumor number } \\
\hline Single & 33 \\
\hline Multiple & 8 \\
\hline \multicolumn{2}{|l|}{ Tumor type } \\
\hline NSCLC & 22 \\
\hline Metastasis & 19 \\
\hline \multicolumn{2}{|l|}{ Primary tumor } \\
\hline Colorectal cancer & 12 \\
\hline $\mathrm{HCC}$ & 3 \\
\hline $\mathrm{RCC}$ & 2 \\
\hline Gastric cancer & 1 \\
\hline Sarcoma & 1 \\
\hline \multicolumn{2}{|l|}{ Previous lung surgery } \\
\hline No & 16 \\
\hline Yes & 25 \\
\hline Ipsilateral & 15 \\
\hline Contralateral & 6 \\
\hline Bilateral & 4 \\
\hline \multicolumn{2}{|l|}{ Tumor characteristics } \\
\hline Number & 51 \\
\hline Maximum tumor size $(\mathrm{cm})$ & $\begin{array}{l}1.7 \pm 1.2 \\
\text { (range } 0.6-6.8 \text { ) }\end{array}$ \\
\hline$<2 \mathrm{~cm}$ & 37 \\
\hline$\geq 2 \mathrm{~cm}$ & 14 \\
\hline \multicolumn{2}{|l|}{ Tumor location (right or left) } \\
\hline Right lung & 26 \\
\hline Left lung & 25 \\
\hline \multicolumn{2}{|c|}{ Tumor lacation (internal or external) } \\
\hline Internal & 17 \\
\hline External & 34 \\
\hline \multicolumn{2}{|l|}{ Contact to major vessel } \\
\hline Yes & 31 \\
\hline No & 20 \\
\hline
\end{tabular}




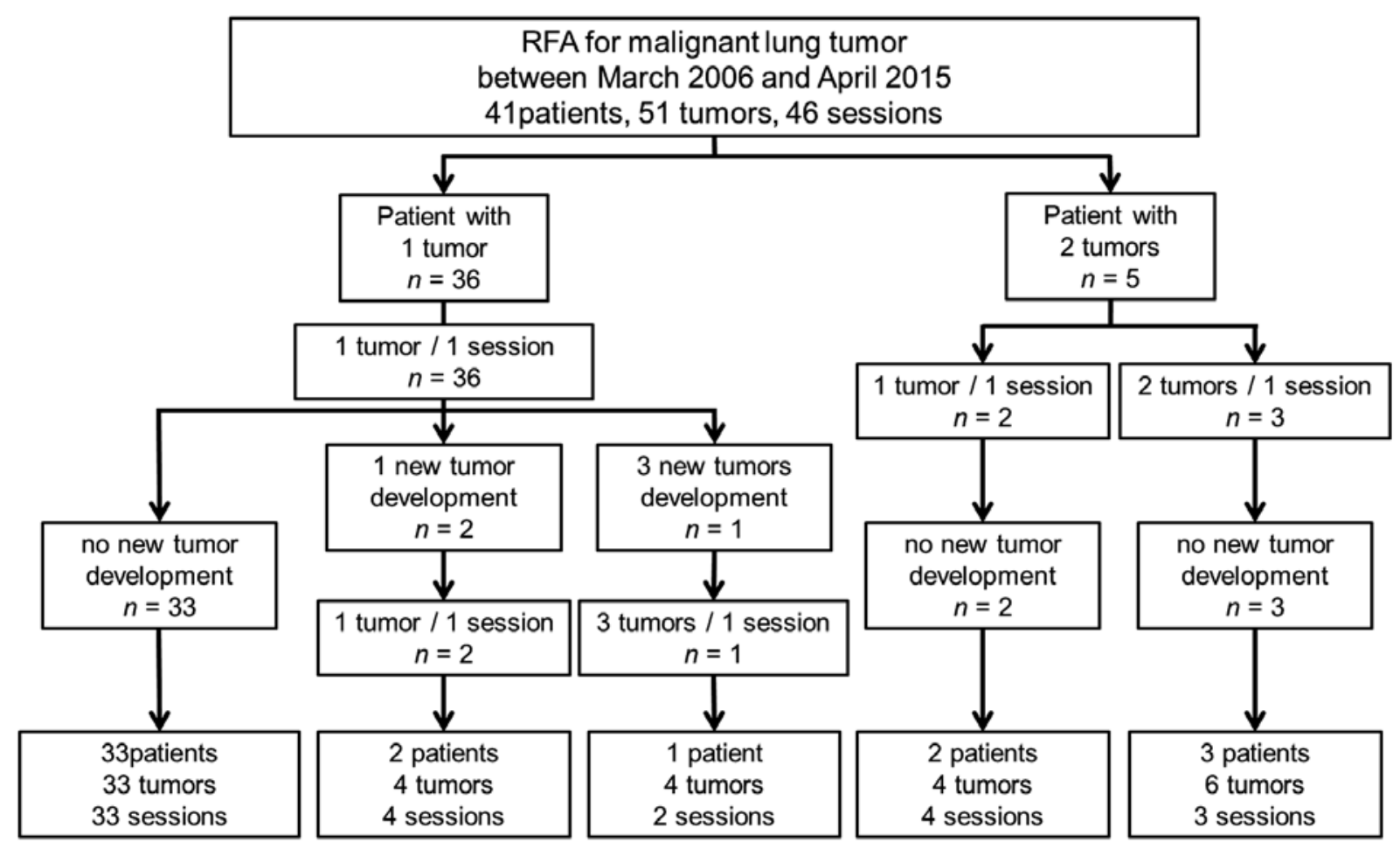

Fig. 1. Flowchart of patients who received lung radiofrequency ablation in this study period

$=1)$, and alveolar soft tissue sarcoma $(n=1)$. Five patients $(12.2 \%, 5 / 41)$ had 2 tumors at the time of initial RFA. Five new tumors developed in 3 patients on follow-up after the initial RFA; these tumors were also treated using RFA. Therefore, 8 patients had multiple lung tumors and RFA was performed on 51 tumors, in total.

A single session of RFA, regardless of the number of treated tumors, was counted as one. Repeated sessions of RFA were performed with an interval of $>30$ days. In total, 46 RFA sessions were performed for 51 tumors (Fig. 1).

The mean maximum tumor diameter was $1.7 \pm 1.2 \mathrm{~cm}$ (range, 0.6-6.8 cm). Twenty-six tumors were located on the right and 25 were on the left. Twenty-five patients $(61.0 \%)$ had previous histories of lung surgery prior to undergoing RFA; ipsilateral, contralateral, and bilateral lobectomy or partial pneumonectomy had been performed on 15,6 , and 4 patients, respectively. The histologic type of NSCLC was diagnosed based on previous surgical specimens $(n=15)$ or percutaneous needle biopsy specimens $(n=7)$. The cancer stages of patients with NSCLC were IA $(n=17)$, IIB $(n=$ $1)$, IIIA $(n=2)$, and IV $(n=2)$ according to the TNM Classification of Malignant Tumors $7^{\text {th }}$ edition [21]. Seven patients with NSCLC and 6 patients with metastatic lung tumor received combination chemotherapy after lung RFA.

At the time of the initial RFA, 7 patients (17.1\%) had extrapulmonary tumors. Four patients with NSCLC had, respectively, bone metastasis $(n=2)$ and lymph node metastasis $(n=2)$. Two patients with pulmonary metastasis from colorectal cancer had, respectively, lymph node metastasis ( $\mathrm{n}$ $=1$ ) and peritoneal metastasis $(n=1)$. All of these tumors were considered to be controlled because of systemic che- motherapy, as they did not show progression during at least 2 months of follow-up. One patient with hepatocellular carcinoma had a viable primary tumor, which was controlled via intra-arterial chemotherapy.

\section{RFA procedure}

Routine physical examination, laboratory tests, and imaging studies, such as chest radiographs and contrast-enhanced whole-body computed tomography (CT) scans, were performed on all patients before RFA.

Lung RFA was performed under moderate sedation and local anesthesia on an inpatient basis by five interventional radiologists with more than 3 years of experience. Pentazocine (Pentagine; Daiichi Sankyo Co. Ltd., Tokyo, Japan) was used for analgesia, and lidocaine (Xylocaine; Astellas Pharma Inc., Tokyo, Japan) was used for local anesthesia. Cefazolin (Astellas Pharma Inc.) was administered before and for two days after RFA as prophylaxis, in accordance with our institutional standards and policies. Real-time CT fluoroscopy (X-Vigor and Aquilion LB; Toshiba Medical Systems Corp., Otawara, Japan) was used to place the electrodes, either internally cooled (Cool-Tip RF Ablation System; Covidien, Boulder, CO, USA) or multi-tined expandable (LeVeen; Boston Scientific, Natick, MA, USA), into the tumor. Internally cooled electrodes were used in 39 of $46(84.8 \%)$ sessions, whereas multi-tined expandable electrodes were used in 7 of $46(15.2 \%)$ sessions. The type of needle was determined according to the decision of the operator. In general, a tumor located adjacent to a large vessel or the diaphragm was treated using cooled electrodes, and large tumors tended to be treated using expandable needles 
as this method can create a larger ablation zone. However, the decision depended mainly on the operator' s preference. The electrode was placed in the center of the tumor, which was punctured again as needed, to ablate the entire tumor, depending on the size and shape. When using internally cooled electrodes, RF energy was applied for 12 minutes using an impedance-control algorithm. When using multi-tined expandable electrodes, RF energy was applied until the impedance showed a rapid increase or until an automatic shutoff occurred after 15 minutes. If the ablation area did not appear to cover the tumor within a safety margin, the electrode was inserted again at the insufficiently ablated area and RF energy was applied until the ablation area appeared to cover the entire tumor, whenever possible. During the procedure, peripheral capillary oxygen saturation was monitored continuously and blood pressure was measured every 5 minutes. Technical success was defined as completion of RFA with a planned treatment protocol and creation of an ablation zone covering the entire tumor, as observed on CT performed immediately after the procedure [22].

\section{Complications}

Complications were evaluated according to the Common Terminology Criteria for Adverse Events (CTCAE) ver. 4.03 [23]. Any patient death occurring within 30 days of lung RFA was designated as Grade 5. Complications within 30 days of lung RFA were defined as major, if Grades 3 or 4 and as minor, if Grades 1 or 2. The diagnosis of emphysema was determined by the Goddard classification [24]. CT was performed immediately after RFA, and chest radiographs were obtained 2 hours, 1 day, and 2 days after RFA to evaluate hemothorax and pneumothorax.

\section{Follow-up}

Follow-up was continued until August 31, 2015, or until patient death, whichever came first. Routine physical examinations and laboratory tests, including measurement of tumor markers based on the primary tumor, were performed every 3 months. After RFA, CT scan, with or without contrast enhancement, was performed at 1 month, then every 34 months for 2 years, and every 6 months thereafter.

Local tumor progression was defined as the appearance of new tumor foci at the edge of the ablation zone after confirmation of adequate ablation of the target tumor on follow-up CT images [22].

\section{Assessment and statistical analysis}

Technical success and complications were evaluated on a per-session basis. The risk factors for pneumothorax were compared using Welch's t-test or Fisher' s exact test. The risk factor variables for pneumothorax were age, sex, tumor size, needle depth, pleural-lesion angle, number of punctures, previous lung surgery, emphysema, and needle type. Local tumor progression rates were evaluated on a pertumor basis. The pleural-lesion angle was defined as an angle between the RF electrode and a line tangential to the pleural surface. Survival was calculated from the time of the initial RFA. Cumulative overall survival curves and local tumor progression curves were generated using the KaplanMeier method. Local tumor progression and survival rates were compared among subgroups of patient backgrounds using the log-rank test. The risk factor variables for local tumor progression were tumor size, tumor origin, needle type, tumor location, contact with major vessels, and learning curve, and those for overall survival were age, sex, tumor size, tumor number, existence of extra pulmonary lesion, achievement of complete ablation, and application of combination chemotherapy. Tumor location was determined as external if the tumor was located in the outer half of the lung and internal if it was in the inner half. A tumor was defined as in contact with major vessels when it was located adjacent to vessels or bronchi larger than $2 \mathrm{~mm}$, Multivariate analysis was performed for local tumor progression and overall survival using a Cox proportional hazards model. Univariate analysis to evaluate risk factors for local progression was also performed after the tumors larger than $3 \mathrm{~cm}$ were excluded from the study population; this was an attempt to reduce the confounding effect of tumor size on selection of needle type. Data were expressed as mean \pm standard deviation. A $p$ value of $<0.05$ was considered statistically significant. Statistical analyses were performed using SPSS for Windows, ver. 21 (SPSS Inc., Albany, NY, USA).

\section{RESULTS}

\section{Lung RFA}

In all 46 RFA sessions, the electrodes were placed into the planned sites and ablation was completed according to the planned protocol. The targeted tumor was completely covered by an ablation zone after initial RFA in 42 of 46 sessions (technical success rate of 91.3\%). In 3 sessions, large tumors $(6.8 \mathrm{~cm}, 5.7 \mathrm{~cm}$, and $4.0 \mathrm{~cm}$, respectively) were not covered by an ablation zone after RFA. In these cases, observation without additional treatment was performed according to the patients' preference. In the remaining one session, it was not possible to achieve an ablation zone to cover a 2.4-cm tumor that had an edge that was adjacent to the pulmonary artery.

\section{Complications}

There were no procedure-related deaths. One patient died 26 days after the procedure (Grade 5) because of pneumonia in the contralateral lung. Grade 2 symptomatic pneumotho$\operatorname{rax}(n=5)$ and hemothorax $(n=1)$, and grade 1 asymptomatic pneumothorax $(n=9)$ occurred during the procedure. Three cases of symptomatic pneumothorax and one case of hemothorax were managed by tube placement without the requirement of further intervention. In the other 2 cases of pneumothorax, the patients reported slight respiratory discomfort, but recovered without any treatment. Post- 
Table 2. Relationship between occurrence of pneumothorax and clinical factors

\begin{tabular}{|c|c|c|c|}
\hline & \multicolumn{3}{|c|}{ Pneumothorax } \\
\hline & Yes & No & p-Value \\
\hline $\begin{array}{c}\text { Age } \\
(\text { mean } \pm \text { SD })\end{array}$ & $68.0 \pm 12.8$ & $66.2 \pm 8.8$ & 0.63 \\
\hline Male/Female & $7 / 7$ & $25 / 7$ & 0.08 \\
\hline $\begin{array}{l}\text { Tumor size } \\
\text { (mean } \pm \text { SD) }\end{array}$ & $15.2 \pm 5.6$ & $19.8 \pm 13.4$ & 0.11 \\
\hline $\begin{array}{l}\text { Needle depth } \\
(\text { mean } \pm \text { SD) }\end{array}$ & $86.7 \pm 22.4$ & $83.4 \pm 21.4$ & 0.64 \\
\hline $\begin{array}{l}\text { Pleura-lesion angle } \\
\quad(\text { mean } \pm \text { SD })\end{array}$ & $18.2 \pm 10.9$ & $25.2 \pm 17.6$ & 0.11 \\
\hline $\begin{array}{l}\text { Number of puncture } \\
\quad(\text { mean } \pm \text { SD) }\end{array}$ & $1.7 \pm 0.8$ & $2.0 \pm 1.3$ & 0.33 \\
\hline $\begin{array}{c}\text { Previous ipsilateral } \\
\text { lung surgery (Yes / No) }\end{array}$ & $3 / 11$ & $21 / 11$ & 0.01 \\
\hline $\begin{array}{l}\text { Previous contralateral } \\
\text { lung surgery (Yes / No) }\end{array}$ & $5 / 9$ & $5 / 27$ & 0.24 \\
\hline $\begin{array}{c}\text { Emphysema } \\
\text { (Yes / No) }\end{array}$ & $7 / 7$ & $5 / 27$ & 0.03 \\
\hline $\begin{array}{c}\text { Type of needle } \\
\text { (expandable / cooled) }\end{array}$ & $1 / 13$ & $6 / 26$ & 0.41 \\
\hline
\end{tabular}

procedure, grade 3 lobar pneumonia in the treated area $(\mathrm{n}=$ 1) occurred after 24 days and grade 2 fever $(n=2)$ occurred after 1 day. Pneumonia was treated using intravenous antibiotics for 6 days, and fever was controlled by administering oral anti-inflammatory agents. Therefore, the major and minor complication rates were $2.2 \%(1 / 46)$ and $37.0 \%$ (17/46), respectively.

Previous ipsilateral lung surgery $(p=0.01)$ and emphysema ( $p=0.03$ ) were determined to be significant risk factors related to the occurrence of pneumothorax. However, tumor size $(p=0.11)$, needle depth $(p=0.64)$, number of punctures $(p=0.33)$, or type of needle $(p=0.41)$ were not found to be significant risk factors for pneumothorax (Table 2).

\section{Tumor progression}

In addition to 4 tumors in which insufficient ablation was achieved, local tumor progression was observed in 4 tumors at 8.8-19.3 months after RFA (mean, $13.2 \pm 4.4$ months) during a mean follow-up period of $20.3 \pm 19.1$ months (range, 0.3-77.3 months). The local tumor progression rates (95\% confidence interval [CI]) were $12.9 \%(3.2-22.8 \%)$ at 1 year and $20.9 \%(7.1-34.7 \%)$ at 3 and 5 years. Tumor size of $\geq 2 \mathrm{~cm}(p=0.01)$ and use of expandable needles ( $p=$ 0.003 ) were found to be risk factors for local tumor progression (Table 3). In contrast, there were no significant differences between NSCLC and metastatic lung tumor ( $p=$ 0.87 ) with respect to local tumor progression. Both tumor size (hazard ratio [HR] 7.0, 95\% CI 1.4-35.3; $p=0.02$ ) and needle type (HR8.9, 95\% CI 1.9-42.8; $p=0.006$ ) retained
Table 3. Local tumor progression rate based on variables

\begin{tabular}{|c|c|c|c|c|c|}
\hline & Tumor & Local $t$ & «mor pro & gression & rate $(\%)$ \\
\hline & number & 1-year & 3-year & 5-year & $\mathrm{p}$-value \\
\hline Tumor size & & & & & \\
\hline$<2 \mathrm{~cm}$ & 37 & 43.5 & 15.2 & 15.2 & 0.01 \\
\hline$\geq 2 \mathrm{~cm}$ & 14 & 38.8 & 38.8 & 38.8 & \\
\hline Tumor type & & & & & \\
\hline NSCLC & 23 & 13.0 & 13.0 & 13.0 & 0.87 \\
\hline Meta & 28 & 11.6 & 24.2 & 24.2 & \\
\hline Needle type & & & & & \\
\hline Cooled needle & 43 & 5.5 & 15.0 & 15.0 & 0.003 \\
\hline Expandable needle & 8 & 50.0 & 50.0 & 50.0 & \\
\hline Tumor location & & & & & \\
\hline Internal & 17 & 5.9 & 5.9 & 5.9 & 0.18 \\
\hline External & 34 & 16.8 & 28.8 & 28.8 & \\
\hline Contact to major vess & & & & & \\
\hline Yes & 31 & 7.6 & 13.4 & 13.4 & 0.15 \\
\hline No & 20 & 21.1 & 32.4 & NA & \\
\hline Learning curve & & & & & \\
\hline First half & 26 & 24.3 & 28.7 & 28.7 & 0.07 \\
\hline Latter half & 25 & 0 & NA & NA & \\
\hline Total & 51 & 13.0 & 20.9 & 20.9 & \\
\hline
\end{tabular}

significance following Cox proportional hazards analysis. The use of expandable needles remained a significant risk factor for local tumor progression $(p=0.02)$ even though tumors larger than $3 \mathrm{~cm}$ were excluded; nevertheless, tumor size did not retain significance $(p=0.88)$.

Additional RFA was performed for 3 of 8 patients with tumors that had shown local progression; these 3 treated tumors were controlled until the end of the follow-up period. The other 5 tumors were not treated because they did not meet the indications for RFA.

\section{Survival}

During a mean follow-up period of $25.3 \pm 20.3$ months (range, 0.9-77.3 months), 11 of 41 (26.8\%) patients (8 cases of NSCLC and 3 cases of metastatic lung cancer) died. The causes of death were systemic tumor progression $(n=9)$ and pneumonia $(n=2)$. In addition to one patient who died of pneumonia 26 days after RFA, one patient died of bilateral pneumonia 20 months after undergoing the treatment. The 1-, 3-, and 5-year overall survival rates were $89.2 \%(95 \%$ CI, 79.1-99.3\%), 61.2\% (95\% CI, 41.1-81.2\%), and $53.5 \%$ (95\% CI, 31.1-75.9\%), respectively (Fig. 2).

The 5-year overall survival rates of patients with NSCLC and metastatic lung tumors were $39.1 \%$ (95\% CI, 13.5$64.3 \%$ ) and $76.1 \%$ (95\% CI, 38.1-92.6\%), respectively. There were no significant differences in survival between 


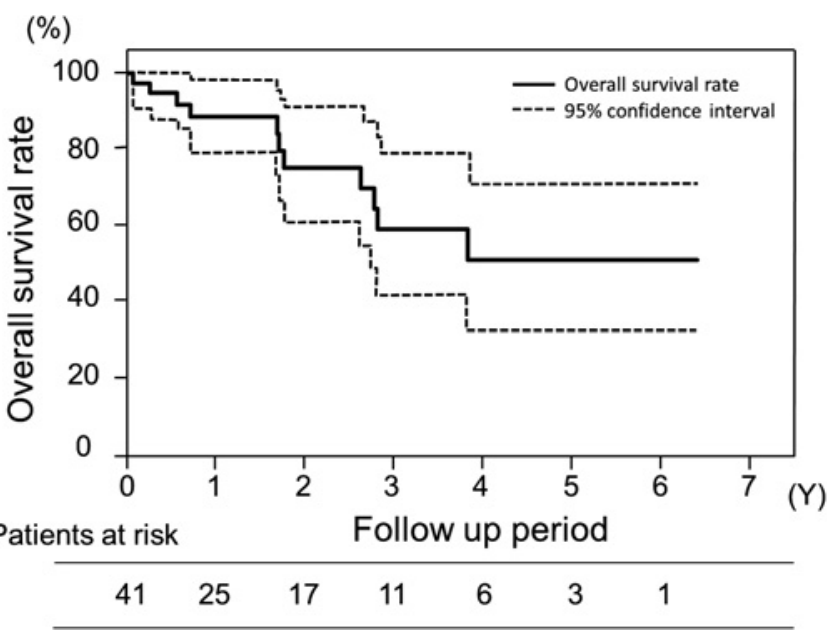

Fig. 2. Kaplan-Meier survival curve of patients who underwent RFA for lung tumor $(\mathrm{N}=41)$. The 1-, 3-, and 5-year overall survival rates were $89.2 \%, 61.2 \%$, and $53.5 \%$, respectively

patients with NSCLC and those with metastatic lung cancer $(p=0.19)$.

Tumor size of $\geq 2 \mathrm{~cm}(p=0.004)$, existence of extrapulmonary tumor $(p=0.02)$, and incomplete tumor ablation ( $p$ $=0.003$ ) were found using univariate analysis to be significantly worse prognostic factors (Table 4). Only tumor size of $\geq 2 \mathrm{~cm}$ (HR 5.1, 95\% CI 1.2-21.9; $p=0.03$ ) retained its significance in the Cox proportional hazards model (Table 5).

\section{DISCUSSION}

Our study showed that lung RFA may be a feasible therapeutic option for selected patients with unresectable lung cancer. The major and minor complication rates based on CTCAE have been reported to be $6-13 \%$ and $28-40 \%$, respectively $[11,12,17]$; our results appear to be comparable with these previous reports. Because lung RFA is principally performed for high-risk non-surgical candidates with advanced age or many comorbid diseases, it is important to be cautious in performing the procedure, and close follow-up after treatment is necessary. Moreover, there is some risk of infection after tissue necrosis from RFA; therefore, although there has been no consensus yet, antibiotic prophylaxis was administered routinely.

As indicated in previous reports, lack of history of ipsilateral lung surgery was found to be a risk factor for the occurrence of pneumothorax [25-27]. Prior ipsilateral lung surgery may reduce the risk of pneumothorax because of postoperative adhesions. Significant differences in the occurrence of pneumothorax between patients with and without emphysema were also observed in the present study, as shown in previous reports $[17,25,28]$.

The 5-year survival rates after lung RFA have been reported to be $27-61 \%$ for NSCLC [11-13] and 20-69\% for metastatic lung cancer [14-16]. Our results seemed to be comparable with these previously reported findings. Tumor
Table 4. Overall survival rate based on variables

\begin{tabular}{|c|c|c|c|c|c|}
\hline \multirow{3}{*}{$\overline{\text { Age (years) }}$} & \multirow{2}{*}{$\begin{array}{l}\text { Patient } \\
\text { number }\end{array}$} & \multicolumn{3}{|c|}{ Survival rate (\%) } & \multirow[b]{2}{*}{$\mathrm{p}$-value } \\
\hline & & \multirow[t]{2}{*}{ 1-year } & \multirow[t]{2}{*}{ 3-year } & \multirow[t]{2}{*}{ 5-year } & \\
\hline & & & & & \\
\hline$<65$ & 18 & 88.2 & 72.3 & 60.3 & 0.39 \\
\hline$\geq 65$ & 23 & 90.0 & 45.0 & 45.0 & \\
\hline \multicolumn{6}{|l|}{ Sex } \\
\hline Male & 29 & 88.8 & 50.5 & 40.4 & 0.14 \\
\hline Female & 12 & 91.7 & 91.7 & 91.7 & \\
\hline \multicolumn{6}{|c|}{ Tumor size } \\
\hline$<2 \mathrm{~cm}$ & 29 & 96.6 & 80.2 & 80.2 & 0.004 \\
\hline$\geq 2 \mathrm{~cm}$ & 12 & 75.0 & 33.8 & 16.9 & \\
\hline \multicolumn{6}{|c|}{ Multiple lung tumor } \\
\hline No & 33 & 86.1 & 54.1 & 40.6 & 0.11 \\
\hline Yes & 8 & 100 & 80.0 & 80.0 & \\
\hline \multicolumn{6}{|c|}{ Tumor type } \\
\hline NSCLC & 22 & 89.5 & 48.8 & 39.1 & 0.19 \\
\hline Meta & 19 & 88.8 & 76.1 & 76.1 & \\
\hline \multicolumn{6}{|c|}{ Extra pulmonary lesion } \\
\hline No & 34 & 92.6 & 70.5 & 56.4 & 0.02 \\
\hline Yes & 7 & 80.0 & 45.7 & 45.7 & \\
\hline \multicolumn{6}{|c|}{ Complete ablation } \\
\hline Yes & 37 & 90.6 & 74.3 & 65.0 & 0.003 \\
\hline No & 4 & 75.0 & 0 & 0 & \\
\hline \multicolumn{6}{|c|}{ Combination chemotherapy } \\
\hline Yes & 13 & 84.6 & 39.6 & 26.4 & 0.07 \\
\hline No & 28 & 91.6 & 82.5 & 82.5 & \\
\hline Total & 41 & 89.2 & 61.2 & 53.5 & \\
\hline
\end{tabular}

NSCLC: Non-small cell lung cancer, Meta: Metastatic lung cancer

Table 5. Result of multivariate analysis for overall survival

\begin{tabular}{lccc}
\hline & \multicolumn{3}{c}{ Hazard } \\
& p-value & ratio & $95 \% \mathrm{Cl}$ \\
\hline Tumor size of 2cm or more & 0.03 & 5.1 & $1.2-21.9$ \\
Existence of extrapulmonry lesion & 0.92 & 1.1 & $0.1-10.3$ \\
Achievement of complete ablation & 0.32 & 3.1 & $0.3-27.7$ \\
\hline Cl: confidence interval & & &
\end{tabular}

$\mathrm{Cl}$ : confidence interval

size was detected as a significant prognostic factor using multivariate analysis. The presence of extrapulmonary tumor was detected as a worse prognostic factor based on univariate analysis, but not on multivariate analysis. These results are consistent with those of previous reports [11, 12, 14-17]. Incomplete tumor ablation was detected as a worse prognos- 
tic factor based on univariate analysis, but not on multivariate analysis, which may be because all of the incompletely ablated tumors were larger than $2 \mathrm{~cm}$. Although there were no significant differences, the overall survival of patients who received combination chemotherapy tended to be shorter than that of those who did not. This finding may be related to the fact that patients who receive chemotherapy have tumors in the advanced stage; however, the interaction was unclear, as patients' backgrounds were heterogeneous in the present study.

The local tumor progression rate after 3 years has been reported to be $18-53 \%[11-13,15,16]$, consistent with our result of $20.9 \%$. Moreover, repeatability of the procedure has been noted to be a strong advantage of lung RFA [12, $13,15,18]$. Aside from being a prognostic factor, tumor size was also detected as a risk factor for local tumor progression. Logically, complete ablation becomes more difficult as a tumor enlarges [19]. In the present study, the use of expandable needles was also detected as a risk factor for local tumor progression. We treated large tumors using expandable needles, and this may have confounded the results. However, the use of expandable needles retained its significant effect on Cox proportional hazards analysis. Moreover, it remained a significant risk factor for local tumor progression even when tumors larger than $3 \mathrm{~cm}$ in size were excluded. The reason for this finding was unclear, but the lower amount of experience with the usage of expandable needles may affect the results.

The present study has some limitations. First, this was a retrospective, single-center study. The small number of patients is another limitation. Third, the inhomogeneous patient series made it difficult to draw conclusions regarding efficacy. Nevertheless, our results suggested that lung RFA was a safe and useful treatment for selected patients with unresectable primary or metastatic lung cancer.

Conflict of interest: The authors declare that they have no conflicts of interest.

\section{References}

1. Torre LA, Bray F, Siegel RL, Ferlay J, Lortet-Tieulent J, Jemal A. Global cancer statistics. CA Cancer J Clin 2012; 65: 87-108.

2. Seo JB, Im JG, Goo JM, Chung MJ, Kim MY. Atypical pulmonary metastases: spectrum of radiologic findings. Radiographics 2001; 21: 403-417.

3. Brant JM. Breathlessness with pulmonary metastases: a multimodal approach. J Adv Pract Oncol 2013; 4: 415-422.

4. Booth S, Moosavi SH, Higginson IJ. The etiology and management of intractable breathlessness in patients with advanced cancer: a systematic review of pharmacological therapy. Nature clinical practice. Oncology 2008; 5: 90-100.

5. Ben-Aharon I, Gafter-Gvili A, Leibovici L, Stemmer SM. Interventions for alleviating cancer-related dyspnea: a systematic review and meta-analysis. Acta Oncologica (Stockholm, Sweden) 2012; 51: 996-1008.

6. Scott WJ, Howington J, Feigenberg S, Movsas B, Pisters K. Treatment of non-small cell lung cancer stage I and stage II: ACCP evidence-based clinical practice guidelines (2nd edition). Chest 2007; 132: 234S-242S

7. National Comprehensive Cancer Network. NCCN Clinical Practice Guidelines in Oncology: Palliative care. Retrieved from http:// www.tri-kobe.org/nccn/guideline/lung/english/non_small.pdf (Accessed 16-Aug-2015).

8. Lumachi F, Mazza F, Del Conte A, Lo Re G, Ermani M, Chiara GB, et al. Short-term survival of patients with lung metastases from colorectal and non-colorectal cancer who underwent pulmonary metastasectomy. Anticancer Res 2015; 35: 3563-3566.

9. Cho S, Song IH, Yang HC, Jheon S. Prognostic factors of pulmonary metastasis from colorectal carcinoma. Interact Cardiovasc Thorac Surg 2013; 17: 303-307

10. Kawashima A, Nakayama M, Oka D, Sato M, Hatano K, Mukai $\mathrm{M}$, et al. Pulmonary metastasectomy in patients with renal cell carcinoma: a single-institution experience. Int J Clin Oncol 2011; 16: 660-665.

11. Simon CJ, Dupuy DE, DiPetrillo TA, Safran HP, Grieco CA, Ng $\mathrm{T}$, et al. Pulmonary radiofrequency ablation: long-term safety and efficacy in 153 patients. Radiology 2007; 243: 268-275.

12. Kodama H, Yamakado K, Takaki H, Kashima M, Uraki J, Nakatsuka A, et al. Lung radiofrequency ablation for the treatment of unresectable recurrent non-small-cell lung cancer after surgical intervention. Cardiovasc Intervent Radiol 2012; 35: 563-569.

13. Hiraki T, Gobara H, Mimura H, Matsui Y, Toyooka S, Kanazawa S. Percutaneous radiofrequency ablation of clinical stage I nonsmall cell lung cancer. J Thorac Cardiovasc Surg 2011; 142: 2430.

14. Yamakado K, Inoue $Y$, Takao M, Takaki H, Nakatsuka A, Uraki J, et al. Long-term results of radiofrequency ablation in colorectal lung metastases: single center experience. Oncol Rep 2009; 22: 885-891.

15. Matsui $Y$, Hiraki T, Gobara H, Iguchi $T$, Fujiwara H, Nagasaka T, et al. Long-term survival following percutaneous radiofrequency ablation of colorectal lung metastases. J Vasc Interv Radiol 2015; 26: 303-310.

16. de Baere T, Auperin A, Deschamps F, Chevallier P, Gaubert Y, Boige $\mathrm{V}$, et al. Radiofrequency ablation is a valid treatment option for lung metastases: experience in 566 patients with 1037 metastases. Ann Oncol 2015; 26: 987-991.

17. Kashima M, Yamakado K, Takaki H, Kodama H, Yamada T, Uraki $\mathrm{J}$, et al. Complications after 1000 lung radiofrequency ablation sessions in 420 patients: a single center's experiences. AJR Am J Roentgenol 2011; 197: W576-580.

18. Kodama H, Yamakado K, Hasegawa T, Fujimori M, Yamanaka T, Takaki H, et al. Radiofrequency Ablation Using a MultipleElectrode Switching System for Lung Tumors with 2.0-5.0-cm Maximum Diameter: Phase II Clinical Study. Radiology 2015; 277: 895-902.

19. Beland MD, Wasser EJ, Mayo-Smith WW, Dupuy DE. Primary non-small cell lung cancer: review of frequency, location, and time of recurrence after radiofrequency ablation. Radiology 2010; 254: 301-307.

20. Oken MM, Creech RH, Tormey DC, Horton J, Davis TE, McFadden ET, et al. Toxicity and response criteria of the Eastern Cooperative Oncology Group. Am J Clin Oncol 1982; 5: 649-655.

21. Goldstraw P, Crowley J, Chansky K, Giroux DJ, Groome PA, Rami-Porta R, et al. The IASLC Lung Cancer Staging Project: proposals for the revision of the TNM stage groupings in the forthcoming (seventh) edition of the TNM Classification of malig- 
nant tumours. J Thorac Oncol 2007; 2(8): 706-714.

22. Ahmed M, Solbiati L, Brace CL, Breen DJ, Callstrom MR, Charboneau JW, et al. Image-guided tumor ablation: standardization of terminology and reporting criteria-a 10-year update. Radiology 2014; 273: 241-260.

23. National Cancer Institute. Common Terminology Criteria for Adverse Events v4.03 (CTCAE) Retrieved from http://evs.nci.nih.gov/ ftp1/CTCAE/CTCAE_4.03_2010-06-14_QuickReference_5x7.pdf (Accessed 16-Aug-2015).

24. Goddard PR, Nicholson EM, Laszlo G, Watt I. Computed tomography in pulmonary emphysema. Clin Radiol 1982; 33: 379387.

25. Okuma T, Matsuoka T, Yamamoto A, Oyama Y, Toyoshima M, Nakamura K, et al. Frequency and risk factors of various compli- cations after computed tomography-guided radiofrequency ablation of lung tumors. Cardiovasc Intervent Radiol 2008; 31: 122-130.

26. Yoshimatsu R, Yamagami T, Terayama K, Matsumoto T, Miura H, Nishimura T. Delayed and recurrent pneumothorax after radiofrequency ablation of lung tumors. Chest 2009; 135: 1002-1009.

27. Kennedy SA, Milovanovic L, Dao D, Farrokhyar F, Midia M. Risk factors for pneumothorax complicating radiofrequency ablation for lung malignancy: a systematic review and meta-analysis. J Vasc Interv Radiol 2014; 25: 1671-1681.e1.

28. Nour-Eldin NE, Naguib NN, Saeed AS, Ackermann H, Lehnert T, Korkusuz $\mathrm{H}$, et al. Risk factors involved in the development of pneumothorax during radiofrequency ablation of lung neoplasms. AJR Am J Roentgenol 2009; 193: W43-48. 